Revista de Antropología Social

ISSN: 1131-558X

http://dx.doi.org/10.5209/RASO 59440

\title{
Bajo el velo de la "elección individual": efecto y justificación de las opresiones conjugadas sobre los trabajadores agrícolas migrantes en EE.UU
}

Holmes, Seth M. 2016. Fruta fresca, cuerpos marchitos: trabajadores agrícolas migrantes en Estados Unidos. Quito-Ecuador: Editorial Abya-Yala.

En la obra que aquí reseñamos, Seth M. Holmes, médico y antropólogo que ya había destacado al publicar previamente artículos sobre el tema (Holmes, 2006; 2007; 2009; 2011; 2012 y Holmes, Jenks, \& Stonington, 2011), nos ofrece una serie de "viñetas etnográficas" en las que se muestran las vidas concretas de los mexicanos indígenas triquis de San Miguel, en el estado mexicano de Oaxaca. Desde una perspectiva holística, que busca y encuentra la relación entre fenómenos globales como el Tratado de libre comercio de América del Norte (NAFTA) y otras políticas económicas neoliberales de las últimas décadas, y la necesidad de migración, pese a los peligros que dicha migración entraña, Seth M. Holmes narra las experiencias de estas personas en su diáspora: al cruzar la frontera, al verse obligados a aceptar trabajos cuyos efectos atroces sobre la salud reporta el antropólogo con minuciosidad, al verse reducidos a la animalidad en dichos trabajos, al ser atendidos con una negligencia "justificada" o "legitimada" por los discursos hegemónicos, al tener que vivir en campos de trabajo cuya insalubridad imposibilita el descanso que el cuerpo necesita...

Pero no se queda aquí: el antropólogo también se preocupa de llevar su etnografía al resto de capas en que se articula el mundo del trabajo agrícola y el sistema sanitario en Estados Unidos. Este enfoque le permite reconocer el efecto de lo macropolítico y lo macroeconómico sobre personas que, en el mejor de los casos, poseen unos ideales éticos contrarios a la situación que se da a su alrededor y una clara intención de mejorar las condiciones en la medida en que su posición en la jerarquía lo permita, pero que, sin embargo, se ven forzadas por la lógica de la competitividad y las estructuras neoliberales a reproducir con mayor o menor sutilidad la situación contra la que querrían luchar. Igualmente, se localiza lo que, apoyándose en Sartre, el autor llama "mala fe", es decir, la asunción colectiva de una ficción justificativa encargada de ocultar la crudeza y la crueldad de la realidad diaria de aquellos que sostienen su calidad de vida. Por último, le permite analizar críticamente la formación sanitaria en cuanto cómplice de la reproducción de esta "mala fe" y de tales condiciones, en la medida en que enseñan al médico a explicar las enfermedades en términos de génesis biológica y/o conductual, pero nunca en cuanto su génesis pueda ser eminentemente sociopolítica, de forma que los individuos o sus culturas (por derivación racista desde lo individual) son responsabilizados de sus enfermedades.

Que los conceptos acríticos, las taxonomías implícitas y las prácticas irreflexivas tienen consecuencias físicas y psicológicas de diverso calado según la posición que cada uno ocupa en el complejo estructural de cada sociedad es algo que todos los que nos interesamos por la antropología tenemos presente. Que la etnografía posee 
la capacidad de desnaturalizar los conceptos y confrontarlos críticamente, minar empíricamente las taxonomías al volverlas explícitas y contrastarlas con una realidad bien diferente, y lograr una responsabilización y toma de conciencia sobre las prácticas cotidianas que desarrollamos en nuestro día a día, tampoco escapa a nuestro conocimiento. Sin embargo, cuando el problema concreto es el de la forma en que esos conceptos acríticos, esas taxonomías implícitas y esas prácticas irreflexivas producen, reproducen y refuerzan todo un abanico de opresiones sobre una de las poblaciones más denostadas en Estados Unidos, los trabajadores agrícolas migrantes, y entre ellos, los últimos en la jerarquía, los mexicanos indígenas triquis, el riesgo de malograr la investigación aumenta considerablemente. Los triquis son una población que tiene que tomar riesgos enormes cruzando la "frontera más violenta del mundo entre dos países que no están en guerra" (McGuire y Georges, 2003) para huir de una muerte lenta por falta de recursos en un país sometido a políticas globales neoliberales depredadoras, que han hundido los cimientos de sus propios medios tradicionales de producción. En este sentido, constituyen una población sometida a opresiones de clase y racistas, entre otras, tanto en su país como en el país en el que han de pasar largas temporadas haciendo el trabajo que nadie quiere hacer. Por ello, cuando el problema concreto es el de la forma en que esos conceptos, taxonomías y prácticas producen un cuerpo del "mexicano indígena" inscribiendo en él los signos de la responsabilidad de su propia situación, nos hallamos frente a una investigación de alto riesgo en al menos tres sentidos: alto riesgo analítico, pues siempre cabe la posibilidad de no hilar suficientemente fino y acabar, en algún punto, siendo cómplice de dichas concepciones, taxonomías y prácticas, así como un alto riesgo positivista, que ante la exigencia de hechos puros olvide el lugar propio del antropólogo, su posición, sus esquemas y su propio cuerpo, como herramienta de trabajo que no sólo no malogra la investigación, sino que es condición de posibilidad de la misma. Pero también alto riesgo personal, pues el método requerido, la observación participante, implica vivir en carne propia el cruce de la frontera, el trabajo a ras de suelo - donde el cuerpo de nadie desea ni merece estar-, incluyendo la conciencia de la injusticia de los privilegios allí donde el propio cuerpo, sus rasgos, el sedimento de una vida previa acomodada, imposibilita el ajuste perfecto al contexto de estudio (págs. 66-70). Que uno nunca pueda ser un indígena triqui ni sufrir el total de su sufrimiento es un hecho que produce casi tantos datos como la experiencia en profundidad de sus condiciones.

Ante estos riesgos, uno no puede menos que felicitar al antropólogo y médico Seth M. Holmes. A lo largo de su etnografía el lector siente crecer exponencialmente la sensación de que es la persona perfecta para encargarse de dicho problema. Su sensibilidad, la precisión de sus análisis, su sólido armazón teórico — pleno en referencias a Pierre Bourdieu, Judith Butler, Louis Althusser, Michel Foucault, Philippe Bourgois, Mary Weismantel, Stephen Eisenman y Nancy Scheper-Hughes, entre muchos otros-, su esmero incansable, su originalidad y, por supuesto, su doble formación en medicina y antropología, le muestran como la persona indicada para encarar los riesgos comentados y salir airoso.

Este último punto, su formación como médico, resulta particularmente pertinente. El antropólogo logra, a partir de dicha formación, desentrañar la conexión implícita entre los procesos económicos que obligan al trabajador agrícola a poner en juego su cuerpo, y la naturaleza concreta de las lesiones que tales condiciones generan. Así, el sufrimiento adquiere una perspectiva holística que no olvida comentar el 
Tratado de libre comercio de América del Norte ni el Tratado de libre comercio de Centroamérica, recapitulando las últimas décadas de historia económica mexicana, ni tampoco los nombres, las espaldas, los estómagos, que sufrieron lesiones concretas, cuya génesis sociopolítica es invisibilizada, hasta el punto que en el historial de un triqui torturado por motivos políticos consta que dicha persona es un "viejo boxeador" - resultado de una comunicación deficiente de la que, por supuesto, los profesionales de la salud culpan sutilmente a la víctima-

El análisis de los dispositivos que posibilitan dicha invisibilización —que es, a su vez, condición de posibilidad de la producción y reproducción de la situación analizada - lleva a Seth M. Holmes a estudiar distintas caras de los mismos: por un lado, los mecanismos materiales-urbanísticos que suponen la ocultación real de los campos de trabajo, por otro, los mecanismos discursivos en los que numerosas categorías y "lugares comunes", dispuestos en contextos técnicos y cotidianos, justifican y/o minimizan a ojos de la población nacional las jerarquías que articulan la división del trabajo y que sostienen su calidad de vida y los efectos de estas jerarquías sobre los cuerpos de quienes están en las posiciones más bajas de las mismas. A su vez, también son descubiertos ciertos mecanismos prácticos, como acoger trabajadores estadounidenses adolescentes como recolectores en condiciones de trabajo favorables y flexibles, de forma que cuando crezcan puedan decir, con la voz henchida de orgullo, que ellos "saben cómo es" el trabajo de piscador', y opinan que "no es tan malo en realidad" (pág. 106).

En cuanto a los mecanismos discursivos, el autor presta especial atención a aquellos que apelan a una retórica de la elección individual. Así, el lector logra comprender el papel que juega en la justificación de dicha jerarquía la distinción, propia de la bibliografía técnica, entre migrantes por motivos políticos (refugiados) y migrantes por motivos económicos (inmigrantes en el sentido usual de la palabra), donde lo fundamental es la retórica que contrapone los primeros, "obligados a migrar por la situación política de su país de origen", a los segundos, vistos como "migrantes por elección personal buscando mejorar su situación económica”. Bien, no está en cuestión el estatuto del refugiado ni los motivos que le llevaron a migrar, pero la etnografía que ocupa esta reseña muestra con creces que el "migrante por motivos económicos" no se opone, como pretende esta bibliografía técnica, al "migrante por motivos políticos". Para el indígena triqui, que ve justificada su posición en la jerarquía y todos los males físicos y psicológicos que esta acarree porque "escogió" migrar, la alternativa, quedarse en San Miguel o en San Pedro, en Oaxaca, habría significado su muerte lenta y la de toda su familia. En las mentes de los inmigrantes indocumentados triquis que convivieron con Seth M. Holmes siempre estaba la supervivencia de sus congéneres allá en Oaxaca: la escolarización de sus hijos, la construcción de una vivienda digna, paliar el hambre de su familia... En las mentes de los estadounidenses cómplices de esa "mala fe" que tematizan Sartre y Seth M. Holmes, los triquis han elegido ir a Estados Unidos a aprovecharse de su seguridad social - una seguridad social a la que la gran mayoría de ellos ni siquiera tienen la posibilidad de acceder - y si no les gusta cómo son tratados, siempre pueden volver por donde han venido. Igualmente sugerente es la interpretación que hace de los carteles que encuentra en Altar, en el norte de México: tras describir los diversos peligros de cruzar la frontera, "serpientes de cascabel, alacranes, insectos del desierto,

Con la voz "piscador" el autor se refiere a quienes se encargan de la cosecha. Esta palabra, traducción casi literal de picker, es mucho más común en la industria agraria de California que "recolector". 
varias especies de cactus, deshidratación y agresores", en todos puede leerse "¿vale la pena arriesgar tu vida?” (pág. 39). Con ayuda de Butler (2010), el antropólogo reflexiona sobre el marco en que está inscrita esta pregunta, el mismo que enmarca los discursos mediáticos sobre las muertes de migrantes en la frontera: este marco arranca la situación de su realidad específica y la resitúa en un contexto donde el cruce de la frontera parece una "decisión individual" que justifica "la ausencia de dolor por aquellos que mueren y la falta de acción para lograr igualdad y cambios significativos" (pág. 49). En definitiva, toda una gestión del luto es llevada a cabo por medio de estos mecanismos discursivos.

De forma similar, en contextos cotidianos se despliegan otros mecanismos discursivos que Seth M. Holmes registra por medio de entrevistas y observación directa: más allá del uso de insultos, común en el trato a los piscadores mexicanos, el antropólogo analiza la forma en que ciertas formas de discurso, como aquel que distingue entre mexicanos "normales" y mexicanos "indígenas", destacando la anormalidad de estos últimos, asociada además a su "suciedad" y su "violencia" — sin reflexión previa sobre las implicaciones que la propia jerarquía, que se fundamenta circularmente sobre dicha distinción, pueda tener en la suciedad y la supuesta violencia que les caracterizan - , operan para naturalizar el orden establecido. Por este camino, los entrevistados acaban por comentar que a los triquis "les gusta trabajar agachados", y que su constitución física les hace idóneos para trabajar a ras de suelo $-\mathrm{y}$ de la idoneidad al merecimiento apenas hay distancia en los razonamientos de a pie-.

Dicho esto, podríamos dedicar un segundo a reflexionar sobre las palabras de Sloterdijk, acerca de ese mundo actual

[...] que no necesita una piel externa consistente [...] Sólo en casos excepcionales materializa sus límites en elemento sólido, como en el caso de la barrera de contención entre México y Estados Unidos, o en el de la llamada barrera de contención entre Israel y Jordania. La instalación de confort erige sus paredes más eficientes en forma de discriminaciones; se trata de paredes de acceso a fondos de dinero, que separan a quienes tienen y quienes no tienen, muros levantados por reparto extremadamente asimétrico de oportunidades vitales [...] Se puede afirmar con buen motivo que el concepto de apartheid, tras su superación en Sudáfrica, se generalizó en todo el ámbito capitalista desligándose de su formulación racista y transformándose en un estado económicocultural dificilmente inteligible (Sloterdijk, 2010: 232).

Atendiendo a esto, uno podría recomendar al filósofo alemán la fantástica etnografía de Seth M. Holmes, de forma que pueda notar cómo ciertas poblaciones - justo aquellas que han de experimentar tanto los "límites sólidos" como esos otros límites fluctuantes y porosos - sufren una "opresión conjugada", concepto acuñado por Philippe Bourgois (1988) para expresar el efecto conjunto de los distintos ejes de opresión: aquel que se articula en torno al concepto de ciudadanía, aquel otro que toma por referente el de raza — ora cultural, ora biológica—- la opresión de clase... Peter Sloterdijk encontrará en la etnografía de Seth M. Holmes un ejemplo de cómo en el ámbito capitalista opera aún a día de hoy un racismo las más de las veces explícito, cuyos efectos no sólo no contribuyen a su desestabilización, sino que, obrando una inversión de causas y efectos, sitúa los efectos sensibles de una vida de sufrimiento a la base de su justificación. Así, el racismo encontrará la prueba palpable de 
que los triquis merecen ocupar los puestos de trabajo que ocupan y ser tratados como son tratados, en el olor de esos cuerpos que no hallan tiempo que dedicar a la higiene, las espaldas desviadas por una vida de rodillas, las piernas cansadas y torpes, la imposibilidad de una comunicación eficiente, causada por políticas sutiles y exigencias laborales, pero atribuida a la "simpleza", etc.

En conjunto, y pese a lo dicho anteriormente sobre sus referentes teóricos, para recomendar su lectura aludiría - y esto es una decisión personal - a su referente ético. En una nota a pie de página, cerca ya del final del libro (pág. 232), Seth M. Holmes cita al filósofo Emmanuel Levinas (1998), para recordar que es nuestra responsabilidad, en cuanto humanos, entender el sufrimiento de otros como inútil, sin sentido, puesto que todo acto de dotar de significado al sufrimiento contribuye a su justificación y reproducción. En definitiva, a esto responde la etnografía de Seth M. Holmes: es la exposición de una enorme cantidad de sufrimiento sin sentido. Por ello, y no solo por la calidad de su escritura o lo ameno de su lectura, merece ser leído. Al riesgo asumido por el antropólogo, a su trabajo incansable y a su búsqueda insaciable, nosotros hemos de responder leyendo atentamente las páginas en las que ha consignado su experiencia, dejando que los conceptos se desnaturalicen, las taxonomías se reconfiguren y las prácticas se reconsideren.

Luis Periáñez Llorente

Universidad Complutense de Madrid luisperi@ucm.es

\section{Bibliografía}

Bourgois, Philippe (1988). "Conjugated oppression: class and ethnicity among guayi and kuna banana plantation workers". American ethnologist, 15(2): 328-348.

Butler, Judith (2010). Marcos de guerra: las vidas lloradas. México: Paidós mexicana.

Holmes, Seth M. (2006). "An ethnographic study of the context of migrant health". PLoS, 3(10): 1776-1793. doi:10.1371/journal. pmed. 0030448

- (2007). "Oaxacans like to work bent over': the naturalization of social suffering among berry farm workers". International Migration, 45(3): 39-68.

- (2009). "Don’t Misrepresent the Triqui". Monterey County Herald.

- (2011). "Structural vulnerability and hierarchies of ethnicity and citizenship on the farm". Medical anthropology, 30(4): 425-449.

- (2012). "The clinical gaze in the practice of migrant health: Mexican migrants in the United States". Social science and medicine, 74(6): 873-881.

Holmes, Seth M.; Jenks, Angela C.; Stonington, Scott (2011). "Clinical subjetivation: anthropologies of contemporary biomedical training". Culture, medicine and psichiatry, 35(2): 163-182.

Levinas, Emmanuel (1998). On thinking-of-the-other: entre nous. New York: Columbia University Press.

McGuire, Sharon; Georges, Jane (2003). "Undocumentedness and liminality as health variables". Advances in nursing science, 26(3): 185-196.

Sloterdijk, Peter (2010). En el mundo interior del capital (Para una teoría filosófica de la globalización). Madrid: Siruela. 